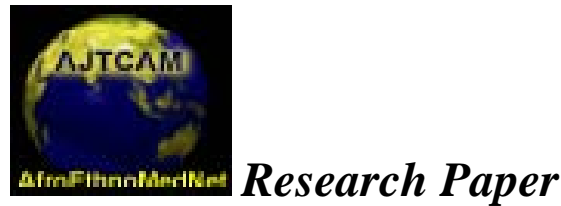

Afr. J. Infect. Diseases

www.africanethnomedicines.net

\title{
ANTI-TRYPANOSOMAL POTENTIAL OF MOMORDICA BALSAMINA LINN FRUIT PULP EXTRACT AGAINST TRYPANOSOMA BRUCEI BRUCEI INFECTION
}

\author{
Abdulkadir Abubakar, ${ }^{1}$ Mgbojikwe Levi. O., ${ }^{3}$ Iliyasu Binta, ${ }^{1}$ Yusuf Aminu. B., \\ ${ }^{1}$ Onyekwelu Nnennaya. A., ${ }^{1}$ Igweh Augustine. C. ${ }^{1}$ Domtur Larry. L. ${ }^{1}$ Timothy A. Gbodi, ${ }^{2}$ \\ Joseph I. Okogun ${ }^{4}$ and Emmanuel O. Ogbadoyi ${ }^{2 *}$ \\ ${ }^{1}$ Biochemistry and Chemotherapy Division, N.I.T.R., P.M.B. 03, Vom, Plateau State. \\ ${ }^{2}$ Biochemistry Department, F.U.T. Minna, Niger State. \\ ${ }^{3}$ Federal College of Animal Health and Production Technology, N.V.R.I. Vom. \\ ${ }^{4}$ Department of Medicinal Plant Research and Traditional Medicine, National Institute for \\ Pharmaceutical Research and Development, Idu, Abuja. \\ *E-mail: eogbadoyi@yahoo.com
}

\begin{abstract}
The search for new trypanocides has not been keenly pursued due to high cost of design and development with no promise of financial returns. Momordica balsamina fruit pulp extract was screened for antitrypanosomal activity in experimental $T$. brucei brucei infection in rabbits. The extract was administered prior to parasite inoculation, 24 hours post parasite inoculation and on establishment of infection. The treatment was by oral administration of the extract at $500 \mathrm{mg} / \mathrm{kg}$ body weight for 14 consecutive days. Parasitaemia was monitored daily while body weight and packed cell volume (PCV) were determined before commencement of studies and subsequently at weekly intervals for 28 days. The result showed a significant $(\mathrm{P}<0.05)$ delay in the establishment of $T$. b. brucei infection in rabbits treated at 24 hours post parasite inoculation. Packed cell volume also increased significantly $(\mathrm{P}<0.05)$ in all treated groups when compared to the untreated group (control). This was less in the group treated on establishment of infection. Administration of the extract to the curative group resulted in body weight gain. The other groups suffered weight loss. The infected but not treated group died at day 39 post infection while those treated before parasite inoculation, 24hours post parasite inoculation, and on the establishment of infection survived for 45 days, 53 days, and 61 days respectively. We conclude that M. balsamina pulp extract reduces anaemia in experimentally infected rabbits.
\end{abstract}

Key words : Momordica balsamina, Chemotherapy, Antitrypanosomal, Trypanosomiasis, Trypanosoma brucei brucei

\section{Introduction}

Trypanosomiasis remains a major public health problem to man and his livestock over much of tropical Africa. It is caused by Trypanosoma species. The disease is difficult to treat and deadly, if untreated. It is difficult to estimate the overall burden of African trypanosomiasis because of under diagnosis in the most heavily infected countries. However, it is believed to be in the vicinity of 100,000 new cases per year, with between $1 / 3$ and $1 / 2$ of cases remaining undetected and untreated (Pepin and Meda, 2001).

Chemotherapy is the most widely used means of controlling the disease. However, effectiveness of the drugs available is limited by a number of factors, which include increasing parasite resistance (Afewerk et al., 2000) and treatment failures, unacceptable toxicity (Akanji and Ngaha, 1989; Triolo, 1990; 
Onyekwelu, 1999) unavailability, logistics of administration, long period of treatment, and high cost. Furthermore, the high cost of developing new drugs, with little hope of a reasonable financial return for their investment in research and development, are serious disincentives for most pharmaceutical companies. In the search for new trypanocides, a wide range of medicinal plants have been screened for antitrypanosomal activity and quite a number of them have been reported to have significant antitrypanosomal activity (Adewumi et al., 2001; Ogbadoyi et al., 2007). Momordica balsamina linn (Curcubitaceae) is an annual or perennial vine belonging to the family cucurbitaceous, indigenous to tropical Africa. It has been used for various ailments and it is believed to possess significant immune boosting effect (Okeke, 2004) and also used as anti-tumor Bourinbaiar, 1995) and anti-HIV agent (Bot, 2004). The phytoconstituents of M. balsamina include glycoside, flavonoid, saponins and resins with glycosides highly present (Abubakar et al., 2005).

There is a significant link between cancer and trypanosomiasis chemotherapy (Barret and Barret, 2000). It is also known that the immune system of the host is usually overwhelmed due to antigenic variation. Since available information on the medicinal use of $M$. balsamina indicate that it possesses antitumor and immune boosting effects, this study was aimed at screening the fruit pulp extract for possible antitrypanosomal property using T. b. brucei infected rabbit as a model. We report here that M. balsamina pulp extract has trypanostatic activity, reduces anaemia and promotes weight gain in experimental trypanosomiasis.

\section{Experimental Animals}

Adult male rabbits (1.69-2.94kg) were purchased from Miango, Plateau state, Nigeria. Animals were handled in compliance with internationally accepted standards for the humane treatment of animals.

\section{Trypanosomes}

Trypanosoma brucei brucei, Federe strain was isolated from cattle at Federe, in Plateau State, Nigeria, and preserved in liquid nitrogen in Parasitology Unit of the Nigerian Institute for Trypanosomiasis Research, Vom, Nigeria.

\section{Plant material}

Ripped M. balsamina fruits were collected within and around Kaduna Vom, Plateau State, Nigeria in November 2006. The fruit was identified by Mallam Abdulkareem of the Federal College of Forestry, Jos, Plateau State, Nigeria, and a specimen was deposited in the college herbarium.

\section{Preparation of the fruit pulp extract.}

Momordica balsamina fruit was cut into two and the pulp containing the seed squeezed out. The seed was separated from the pulp using a wire mesh to obtain the pulp extract. The extract was dried in an oven at $50^{\circ} \mathrm{C}$ for $36 \mathrm{hrs}$. The yield was $32.11 \%$. The dried extract was kept in the refrigerator until required.

\section{Parasite inoculation.}

Fifteen (15) adult male rabbits were weighed and divided into 5 groups (A - E) of 3 rabbits each. A stabilate of $T$. b. brucei taken from liquid nitrogen was inoculated into donor rats. Heavily infected blood sample from donor rats was collected through ocular vein puncture and immediately diluted with physiological saline to give $1 \times 10^{7}$ parasites per ml to obtain inoculums. Healthy rabbits (groups A - D) were then inoculated with $0.1 \mathrm{ml}$ of the diluted blood sample containing $1 \times 10^{6}$ trypanosome cells. Group A animals were pretreated with the extract for 14 consecutive days prior to parasite inoculation. Group E was not infected. Infection was monitored daily by wet film examination of blood sample taken from marginal ear veins of infected animals. 


\section{Administration of extract}

Administration of extract to group B commenced at $24 \mathrm{hrs}$ post parasite inoculation while group C was at establishment of infection. Group D animals were only inoculated with the parasite but not treated with the extract while the group E animals were neither inoculated nor treated. Groups D and E served as positive and negative controls respectively. All administrations were through oral route at $500 \mathrm{mg} / \mathrm{kg}$ body weight for 14 consecutive days.

\section{Therapeutic Effects of extract on infected animals}

This was done by monitoring the weight of all the animals, determining the packed cell volume (PCV), and parasitaemia of the animals. PCV was determined using the haematocrit centrifuge technique while parasitemia was determined daily as described by Herbert and Lumsden (1976).

\section{Results \\ Parasitemia}

The results are presented in Figures 1-3. There were fluctuations in the level of parasitaemia of all the treated groups, which were however, kept at relatively very low level. The prepatent period for the group treated at 24 hours post parasite inoculation was 5-11 days while for other groups it was 5-7 days. When compared to the infected but untreated control, the treatment resulted into the prolongation of life by 6, 14 and 22 days for groups A, B and C respectively. Treatment of the infected group also resulted in the improvement in PCV when compared with the infected but untreated. The treated animals gained weight while the untreated animals suffered weight loss (Figures 4-6)

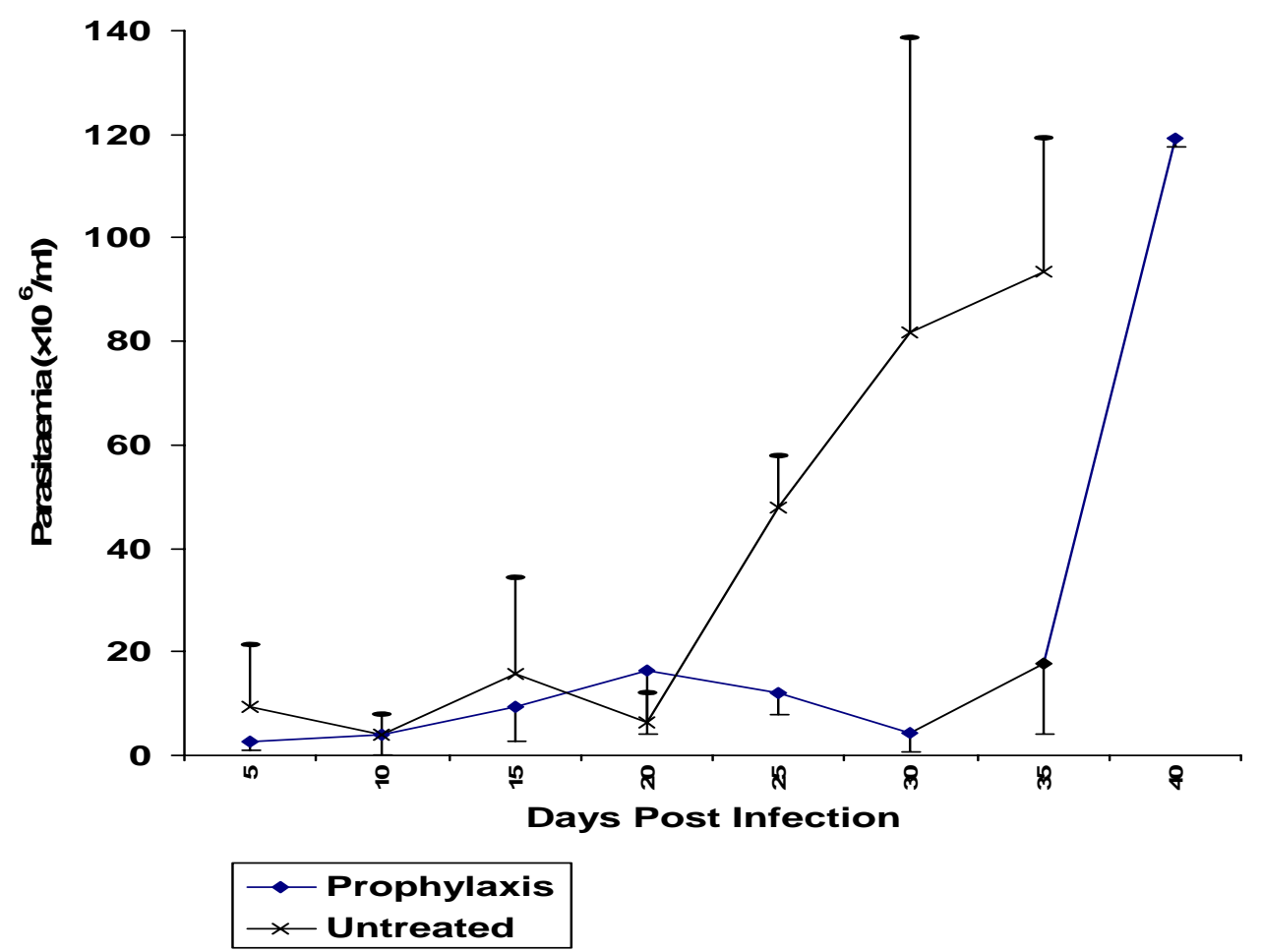

Figure 1: Changes in parasitaemia $\left(\times 10^{6} / \mathrm{ml}\right)$ of $T$. b. brucei infected rabbits and prophylactically treated with $M$. balsamina pulp extract 


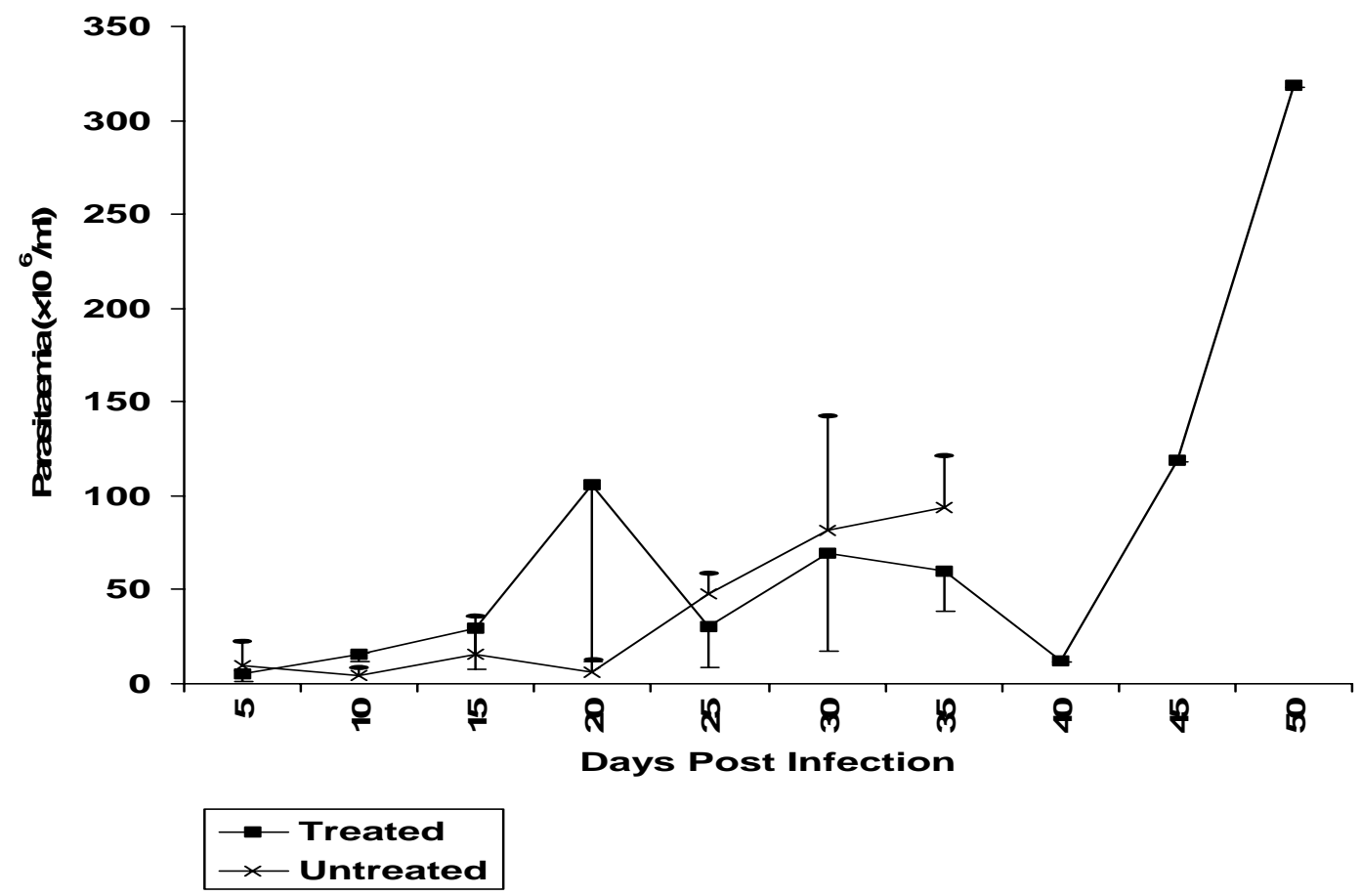

Figure 2: Changes in parasitaemia $\left(\times 10^{6} / \mathrm{ml}\right)$ of $T$. $b$. brucei infected rabbits and treated at 24 hours post inoculation with pulp extract of M. balsamina. 


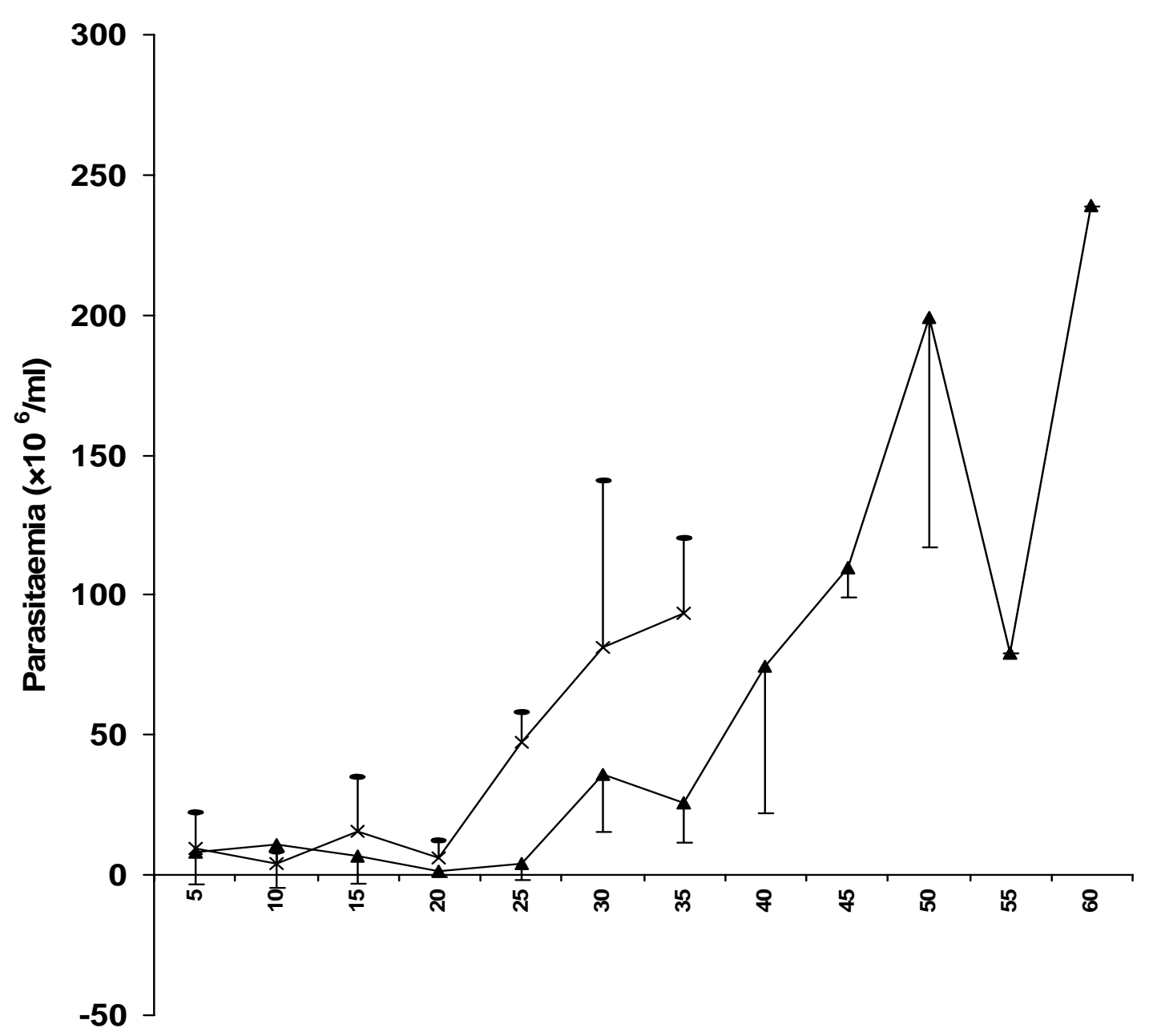

\section{Days Post Infection}

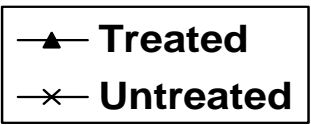

Figure 3: Changes in parasitaemia $\left(\times 10^{6} / \mathrm{ml}\right)$ of T. b. brucei infected rabbits and treated with establishment of infection with $M$. balsamina pulp extract 


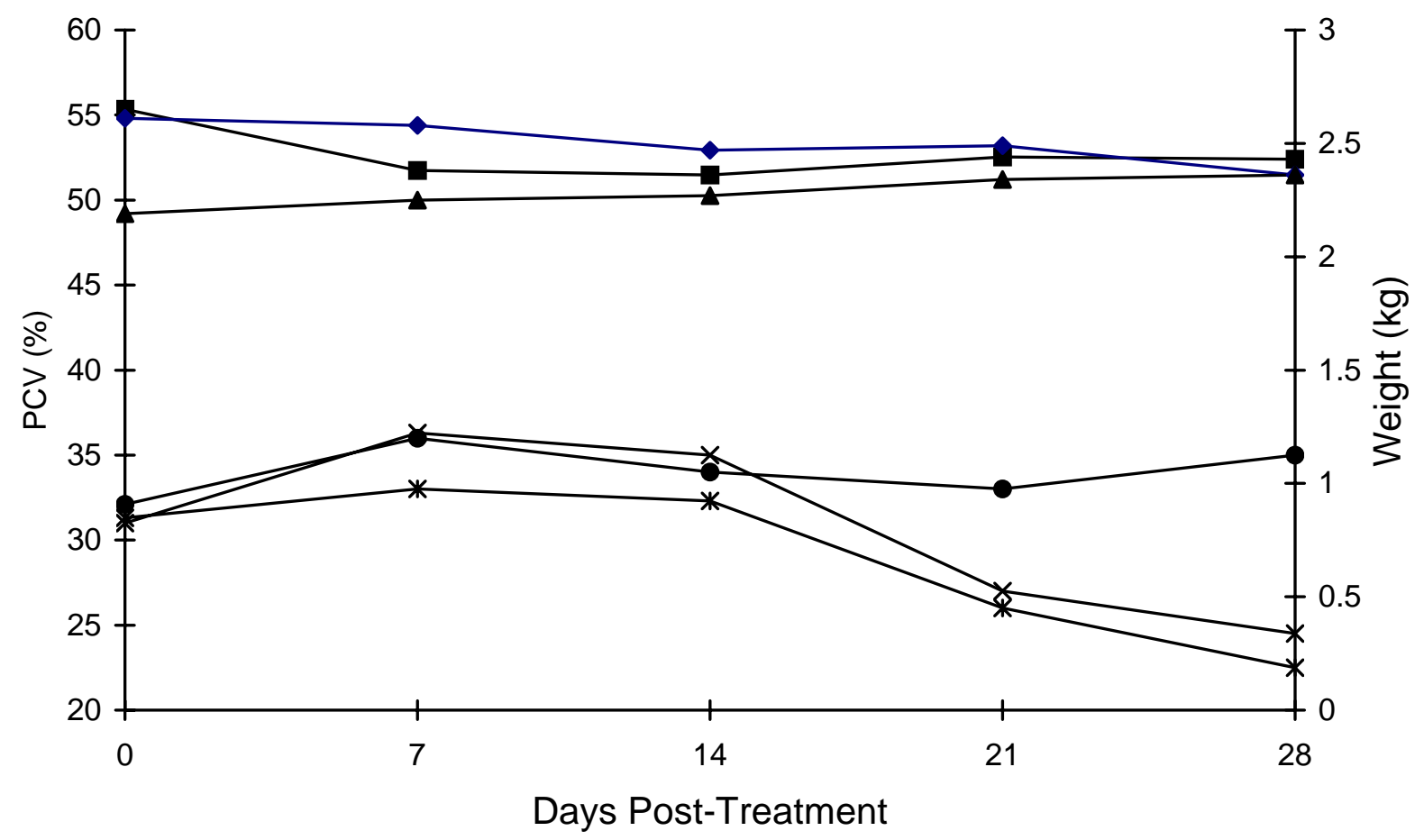

$\rightarrow$ PCV treated

* PCV untreated

$\rightarrow-P C V$ uninfected, untreated

$\rightarrow-$ Wt. treated

$\longrightarrow$ Wt. untreated

$\neg$ Wt. uninfected, untreated

Figure 4: PCV and weight of infected rabbit and prophylactically treated with $M$. balsamina pulp extract. 

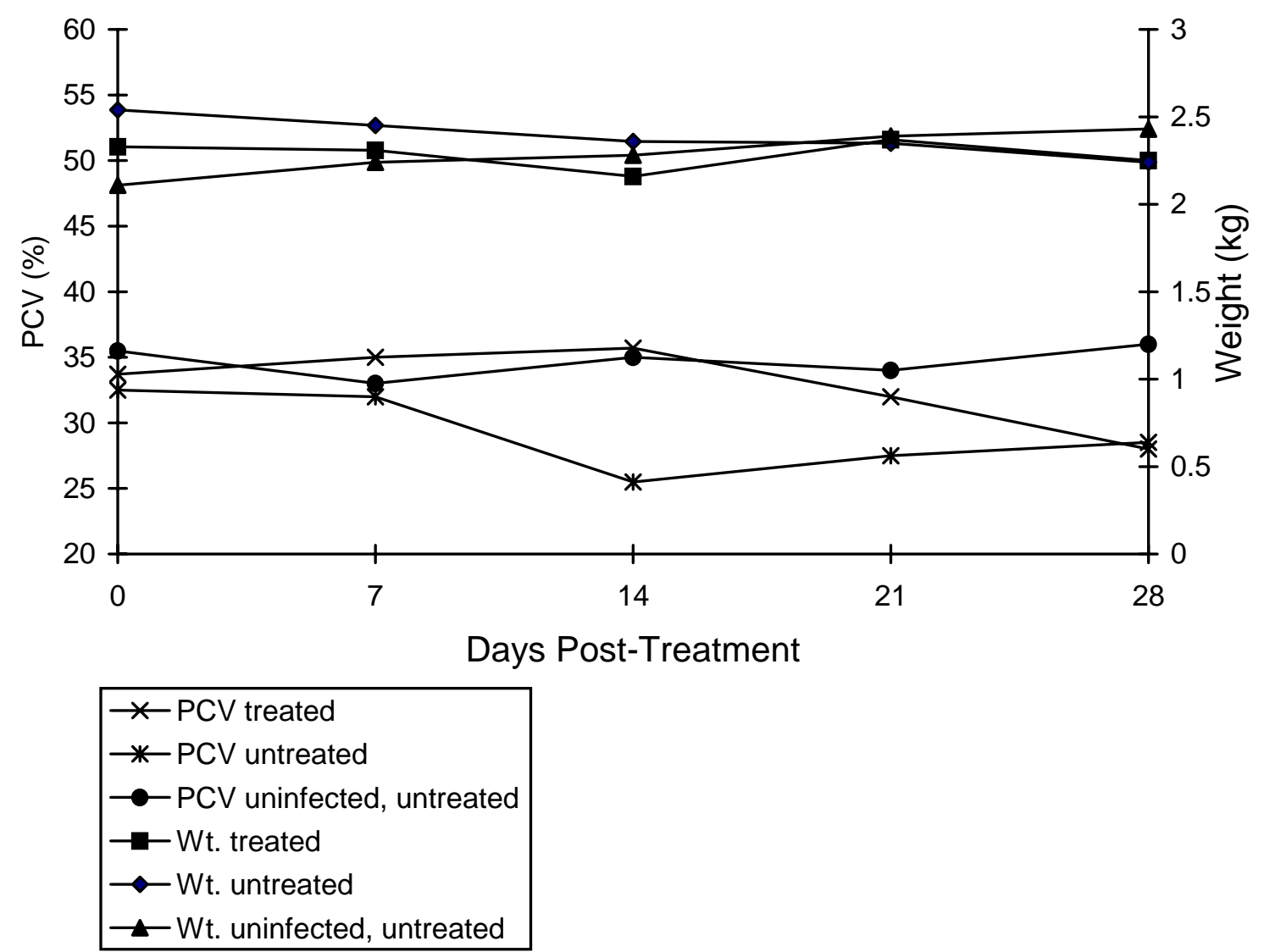

Figure 5: PCV and weight of infected rabbit and treated at 24 hours post inoculation with M. balsamina pulp extract. 

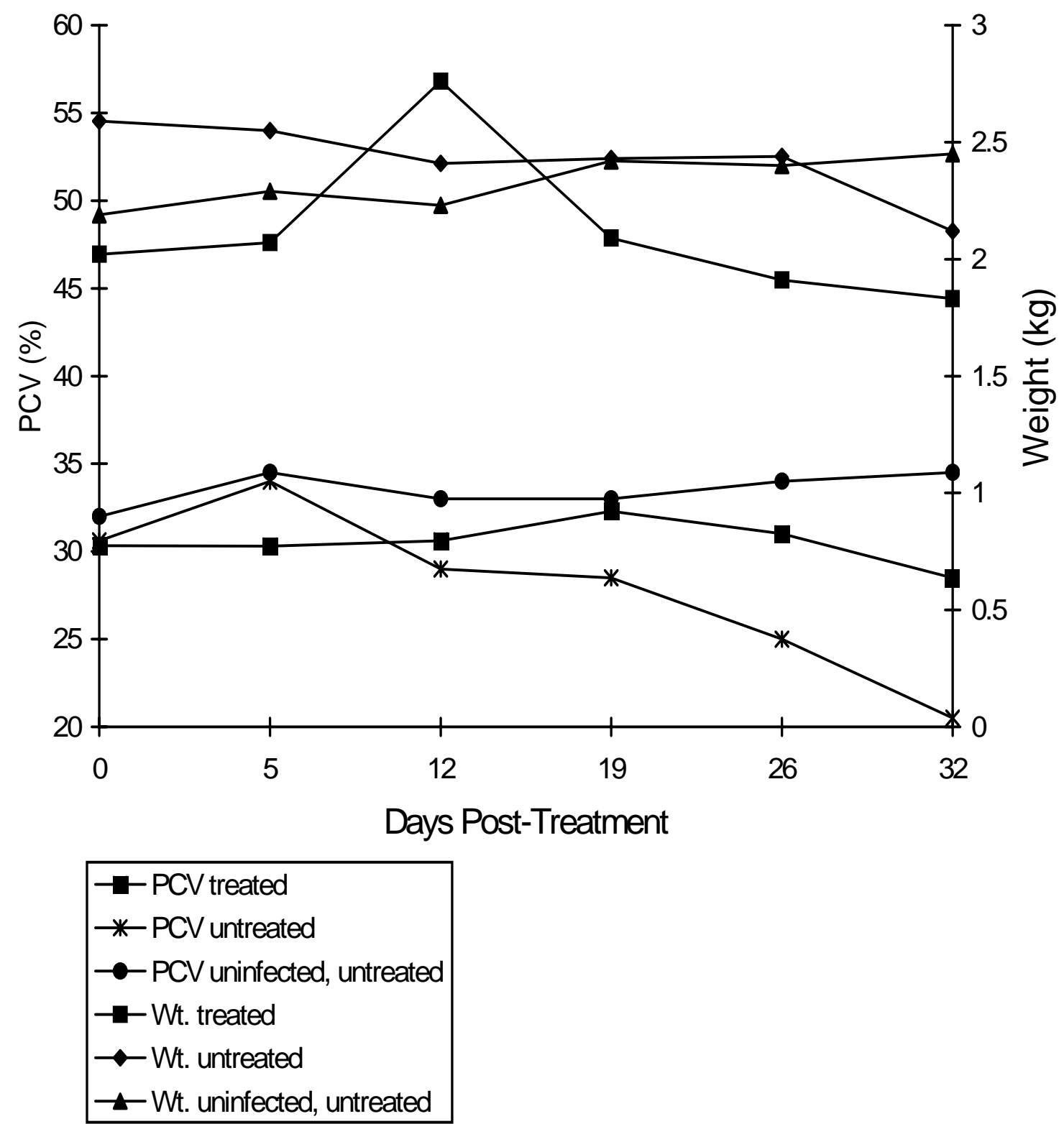

Figure 6: $\mathrm{PCV}$ and weight of infected and treated rabbit at the establishment of parasitaemia with $M$. balsamina pulp extract.

\section{Discussion}

The result of this study showed that $M$. balsamina pulp extract has potential in the management of African trypanosomiasis due to $T$. brucei. The pulp extract of this plant has shown some level of antitrypanosomal activity by prolonging the prepatent period of animals treated after 24 hours post parasite inoculation. There was also the extension of life of all the treated groups beyond that of the untreated control. However, it was observed that the prolongation of life conferred by the extract was highest in animals treated on the establishment of infection while the pretreated group recorded the least survival 
period. What this suggests is that the extract strengthened the host defense, which was already activated because of the presence of parasites in circulation in the rabbits with established infection. This observation is of particular interest because M. balsamina pulp extract was earlier reported to boost immune system (Okeke, 2004). It is therefore likely that the pulp was able to elicit the production of antibodies in the presence of parasites in circulation. This, taken together with the longer prepatent period observed in $24 \mathrm{hrs}$ treated animals suggests that the extract may positively influence the defense capacity of the treated animals. It may well be that the extract enhanced phygocytosis. The net effect of all these was the resultant prolongation of the lives of the treated animals as a consequence of the parasites being kept in check.

The observed trypanostatic effect of the extract was accompanied by corresponding increase in PCV. Anaemia is the most outstanding clinical and laboratory feature of African trypanosomiasis (Suliman and Fieldman, 1989) and also the primary cause of death (Losos and Ikede, 1972; Mamo and Holmes, 1975). Anemia as indicated by PCV level is known to worsen with increasing parasitaemia (Ogbadoyi et al., 1999). The prolongation of lives of treated animals may therefore also be associated with the ability of this extract to improve the PCV possibly by reducing the parasite load or neutralizing the toxic metabolites produced by trypanosomes.

The positive effect of the extract particularly on the curative group can further be deduced from the weight status of the animals. At two weeks post treatment, animals in the curative group gained weight by $1 \%$; while the pretreated group and the group treated $24 \mathrm{hrs}$ post parasite inoculation lost weight by $12.3 \%$ and $7.9 \%$ respectively. This observation indicates that the animals in the curative group were in a better physical state to eat more than those in the other groups. They were therefore more able to resist weight loss that is usually associated with trypanosomiasis.

M. balsamina pulp extract has being reported to have anti-tumor, anti-HIV, and antiplasmodial effects (Bourinbaiar, 1995; Bot, 2004, Benoit-Vical et al., 2006 ). These reports are of interest to us in two respects. The anti-tumour activity is particularly exciting because all four drugs currently used clinically in the treatment of sleeping sickness are known to have some level of anti-cancer activities (Barret and Barret, 2000). Hitherto, drug developers are reluctant to invest in research and development of drugs for the treatment of African trypanosomiasis alone for lack of profitable market.

Therefore, the antiplasmodial and anti-HIV activities taken together with the anti-tumour activity may generate the much needed interest in potential investors to invest in research and development of ethnomedicine and/or synthesis of modern pharmaceuticals from lead compounds that may be obtained from extracts of this plant.

In conclusion, this study has provided evidence that $M$. balsamina fruit pulp extract is trypanostatic, reduces anemia and promotes weight gain in experimental African trypanosomiasis. It is potentially a useful antitrypanosomal agent. Further work is in progress to determine the full effect it has on larpine trypanosomiasis.

\section{Acknowledgement}

The authors are grateful to Elisha Tiyagnet for the typesetting and graphics of the manuscript and E. C. Dung for her technical assistance.

\section{References}

1. Abubakar A, Iliyasu B, Yusuf A.B, Onyekwelu N. A , Igweh, A. C., Shamaki B.U, Afolayan D.O and Ogbadoyi E.O (2005) Antitrypanosomal and hematological effects of selected Nigerian medicinal plants in wistar rats. BIOKEMISTRI 17: 95-99

2. Adewumi, C.O., Agbedahunsi, J.M., Adebajo, A.C., Aladesanmi, A.J., Murphy, N., and Wando, J. (2001). Ethno-veterinary medicine: screening of Nigerian medicinal plants for trypanocidal properties. Journal of Ethnopharmacology 77: 19-24.

3. Afewerk, Y., Clausen, P.H., Abebe, G., Tilahun G., and Mehlitz, D. (2000). Multiple drug resistant Trypanosoma congolense populations in village cattle of metekel district, northwest Ethiopia. Acta Tropica $76: 231-238$

4. Akanji M.A and Ngaha E. (1989). Effect of repeated administration of Berenil on urinary enzyme secretion with corresponding tissue patterns in rats. Pharmacology and Toxicology 64: 272-275 
5. Barrett S.V. and Barrett M.P. (2000). Anti-sleeping sickness drug and cancer chemotherapy. Parasitology Today 16: 7-9

6. Benoit-Vical, F., Grellier, P., Abdoulaye, A., Moussa, I., Ousmane, A., Berry, A., Ikhiri, K., Poupat, C. (2006). In vitro and in vivo antiplasmodial activity of Mormodica balsamina alone or in a traditional mixture. Chemotherapy 52 (6): 288-292

7. Bot Y.S. (2004). Screening for the anti HIV properties of the fruit pulp extract of M. balsamina MMLS Dissertation submitted to the Ambrose Alli university, Ekpoma.

8. Bourinbaiar AS e Lee-Huang S (1995). Potentiation of Anti-Hiv Activity of Anti-inflammatory Drugs, Dexamethasone and Indomethacin, by MAP30, the Antiviral Agent from Bitter Melon. Biochemical Biophysical Research Communication 208: 779-785

9. Herbert W.J and Lumsden W.H.R. (1976). Trypanosoma brucei: A rapid matching method for estimating the host's parasitemia. Experimental Parasitology 40: 427-431.

10. Losos G.J. and Ikede, B.O. (1972) . Review of the pathology of domestic and laboratory animals caused by T. congolense, T. vivax, T. brucei, T. rhodesiense, and T. gambiense. Veterinary Pathology 9: $1-71$

11. Mamo E . and Holmes P . (1975). The erythrokinetics of zebu cattle chronically infected with T. congolense. Research in Veterinary Sci. 18: 105-106.

12. Ogbadoyi, E.O., Agwu I. Ukoha, and Elizabeth Keywalabe (1999) Anemia in experimental African Trypanosomiasis. The J. Protozoology Res. 9(2): 55-63.

13. Ogbadoyi, E.O., Akinsunbo O. Abdulganiy, Theophilus, Z. Adama, Joseph, I. Okogun (2007). In vivo Trypanocidal Activity of Annona senegalensis Leaf Extract Against Trypanosoma brucei brucei. J.Ethnopharmacol. 112: 85-89

14. Okeke, N. (2004). The haematological properties of $M$.balsamina fruit pulp extract in rabbits. BMLS project, College of Medical Laboratory Sciences, University of Jos, Nigeria.

15. Onyekwelu, N.A. (1999). Toxicity of existing trypanocides. A review: West Afr. J. Pharmacol.Drug Res.15: $1-6$

16. Pepin J. and Meda. H.A.(2001).The epidemiology and control of human African trypanosomiasis. Advances in Parasitol. 49: 71-132

17. Suliman H . B. and Fieldman B.F.(1989). Pathogenesis and aetiology of anaemia in trypanosomiasis with special reference to T. brucei and T. evansi. Protozoology Abstracts 13: 37-45

18. Triolo N. (1990). A case of coma due to Arsobal in a newborn affected with congenital T.gambiense. Therapy Infect.Dis. 5: 165-166 